\title{
LA BASE DE MANTA, EL PLAN COLOMBIA Y LOS MILITARES ECUATORIANOS
}

\author{
Dr. Manuel Salgado Tamayo
}

\section{Los acuerdos sobre la Base de Manta}

n el ya largo debate sobre las implicaciones del Plan Co-

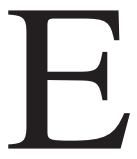
lombia y los acuerdos sobre la Base de Manta, que se inició a fines del año de 1999, se ha podido advertir que, los militares ecuatorianos, de las diversas ramas y jerarquías de las Fuerzas Armadas, tanto en servicio activo como pasivo, no tienen una posición única sobre este delicado asunto de la vida política nacional e internacional. Al parecer, las desventuras se iniciaron con el hermetismo con el que el gobierno de Jamil Mahuad Witt buscó tratar el asunto, en una reedición de las viejas prácticas de la diplomacia internacional secreta. Voceros de ese gobierno, en 1999, trataron de negar la existencia de un acuerdo con los Estados Unidos sobre la Base de Manta. Las protestas y presiones desarrolladas por varios sectores sociales obligaron al Presidente del Congreso Nacional, Juan José Pons, a solicitar, con fecha 6 de mayo de 1999, un informe al Ejecutivo:

Respecto a las razones por las cuales se suscribió un Acuerdo con el Gobierno de los Estados Unidos de América para el empleo de la infraestructura de la Base de la Fuerza Aérea Ecuatoriana en Manta en la lucha contra el narcotráfico'.

En respuesta al pedido del titular del Congreso, los ministros José Ayala Lasso, de Relaciones Exteriores y José Gallardo Román, de Defensa Nacional entregaron un informe, de 12 páginas, sobre la concesión de facilidades logísticas a la Fuerza Aérea de los Esta-

\footnotetext{
* Profesor de la Facultad de Ciencias Económicas de la Universidad Central del Ecuador, Ex Vicepresidente del H. Congreso Nacional del Ecuador.

${ }^{1}$ Ver Oficio No. 8668-68/99 GM7SP, del 12 de mayo de 1999. Archivo Legislativo.
} 
dos Unidos en Manta para el combate al tráfico internacional ilícito de narcóticos. Informe en el que se demuestra que el Gobierno ecuatoriano está consciente de que la entrega de la Base de Manta se hace para reemplazar la pérdida de la Base norteamericana Howard, en Panamá, en cumplimiento de los Tratados TorrijosCarter. Repasemos algunos acápites del texto de ese informe:

Las operaciones que conducía la Fuerza Aérea de los Estados Unidos de América desde la Base Howard, en Panamá, para control y detección del tráfico aéreo ilícito de narcóticos en la región, cesaron el 1 de mayo de este año, con la entrega de dichas instalaciones al gobierno de Panamá como parte de los Acuerdos Torrijos-Carter para la devolución del Canal de Panamá que se hará efectiva el 31 de diciembre de este año.

Los ministros ecuatorianos señalan en su informe que, el Departamento de Estado y el Comando Sur del Ejército de los Estados Unidos de América tienen un gran interés de seguir manteniendo el control efectivo de la región en base a la cooperación internacional. Por lo pronto, agregan, los Estados Unidos han concluido acuerdos temporales con el gobierno de los Países Bajos para utilizar bases en Curazao y Aruba -Anexo 2- y con Ecuador en Manta.

Por desgracia a los Ministros no se les ocurre preguntarse por qué un gobernante de un país pequeño como Panamá había hecho del rescate de la soberanía en la zona del Canal y el desmantelamiento de las bases militares una causa de unidad y esperanza nacional y, al parecer, ni siquiera se percataron de que el gobierno de los Países Bajos cedió soberanía en sus colonias en el Caribe.

Del texto del mismo informe se desprende que entre el Ecuador y los Estados Unidos de América existen 10 convenios bilaterales para la lucha contra el narcotráfico, por lo cual se puede concluir que no era necesaria la entrega de la Base de Manta.

El Gobierno norteamericano, al parecer, midió bien las crecientes dificultades causadas a la economía y la sociedad ecuatorianas por dos décadas de políticas de ajuste estructural, impuestas por 
el Fondo Monetario Internacional, así como las debilidades éticas y cívicas del régimen de Mahuad que lo transformaron en instrumento dócil de las mafias bancarias y de los designios imperiales.

\section{El Acuerdo del 1 de abril de 1999}

En enero de 1999 miembros de las Fuerzas Armadas de los Estados Unidos mantuvieron contactos con altos funcionarios del Ministerio de Defensa del Ecuador para explorar la posibilidad de que se les conceda la Base de Manta. En febrero realizaron las consultas entre la Embajada de los Estados Unidos en Quito y la Cancillería y el Ministerio de Defensa. El 17, 18 y 19 de febrero una delegación norteamericana, encabezada por el embajador Richard Brown, llegó al país, se reunió con los delegados de CanciIlería y Defensa Nacional con los que analizó el proyecto de Acuerdo.

Mientras se desarrollaban todas estas gestiones diplomáticas, ha recordado el Coronel (r) Edison Sánchez, figura destacada de los acontecimientos del 21 de enero del 2000, que varios jefes militares de la Academia de Guerra del Ejército, elaboraron un Informe sobre los escenarios que se crearían para el Ecuador al ceder la Base de Manta e involucrarse en el Plan Colombia. Sánchez recordó que las conclusiones fueron contrarias a la entrega de la Base de Manta a los norteamericanos, pero que el alto mando militar decidió ignorar esas conclusiones².

El 31 de marzo la Embajada de los Estados Unidos presentó a la Cancillería el proyecto de Acuerdo. Ese mismo día, con una velocidad supersónica, el Acuerdo fue remitido y consultado con el Ministerio de Defensa que, en la misma fecha, comunicó por escrito que las Fuerzas Armadas no tienen objeción.

Al día siguiente, 1 de abril, la Cancillería contestó a la Embajada Americana aprobando el proyecto. Así, mediante un simple inter-

2 Kinntto Lucas, Ecuador: Una base militar aumenta amenaza de guerra.

http:www.pce.es/ECUADOR/ecuador 19 htm 29 de enero 2002. 
cambio de notas, casi telegráficas, se constituye un Acuerdo por el cual:

1.- Se concede el acceso y uso de las instalaciones de la Base de Manta a personal militar y civil de los Estados Unidos, para la realización de operaciones ampliadas, que consistirían en el envío de aeronaves y personal militar de los Estados Unidos, en rotación temporal... Las operaciones en dicha localidad se iniciarán antes del 1 de abril, al amparo de las disposiciones contempladas en el intercambio anual de notas entre los gobiernos de Estados Unidos de América y de la República del Ecuador que rigen los ejercicios militares.

Las voces de protesta y las sospechas de que el Ecuador, sumido en una de las crisis más profundas de su historia, había firmado un acuerdo militar que nos comprometía en el largo y doloroso conflicto colombiano, obligaron a los Estados Unidos y al gobierno del Ecuador a elaborar un nuevo Acuerdo en el que tuvieron el cuidado de corregir las falencias y dudas que suscitó en Acuerdo del 1 de abril.

\section{El Acuerdo del 12 de noviembre de 1999}

Los funcionarios de la Embajada Americana en Quito y el propio gobierno de Mahuad sabían que la suscripción de un Acuerdo internacional que implique una alianza militar con los Estados Unidos y la cesión de soberanía podía encontrar voces de resistencia y dignidad tanto en la Junta Consultiva de Relaciones Exteriores, en el Tribunal Constitucional y, sobre todo, en el Congreso Nacional. Los medios de comunicación del Ecuador, en esos días, reflejaron esa expectativa. Para superar estos escollos el Imperio utilizó a un personaje eficiente y siniestro, Heinz Moeller, el hombre de la charlatanería supersónica ${ }^{3}$, quien logró que la Comisión de Asuntos Internacionales y Defensa Nacional, de la que era su Presidente, resuelva que el Acuerdo no necesita de la aprobación por parte del Congreso Nacional.

${ }^{3}$ La adjetivación le pertenece al escritor Edmundo Rivadeneira. 


\section{Se fragua una traición a la Patria}

Reconstruyamos lo que sucedió en la Comisión Especial de Asuntos Internacionales y Defensa Nacional, apoyándonos en el texto del Informe:

La Comisión Especializada Permanente de Asuntos Internacionales y Defensa Nacional se reunió en sesión extraordinaria el martes 9 de noviembre de 1999, presidida por Heinz Moeller y con la presencia de los diputados miembros Sixto Durán Ballén, Pascual del Cioppo, Elba González, Hugo Moreno, Clemente Vásquez y los legisladores Simón Bustamante y Marcelo Farfán. En la sesión se escucharon los informes del Canciller Benjamín Ortiz Brennan y del Ministro de Defensa José Gallardo sobre el "Proyecto de Acuerdo, que se ha negociado entre los Gobiernos del Ecuador y Estados Unidos, para la concesión por diez años del ejercicio del derecho de acceso y uso por parte de los Estados Unidos de las instalaciones de la Base de la Fuerza Aérea Ecuatoriana en la ciudad de Manta".

En la misma sesión se resuelve:

Considerar que este proyecto de Acuerdo no se enmarca en ninguno de los seis numerales previstos en el artículo 161 de la Constitución Política de la República y que por tanto, no necesita la aprobación por parte del Congreso Nacional, por lo que se resue/ve hacer conocer al señor Presidente del Honorable Congreso Nacional su recomendación para que el Proyecto de Acuerdo...sea remitido al Ejecutivo para su debida suscripción". "Este informe, dice textualmente, asi como su resolución fue aprobado por unanimidad en la sesión extraordinaria del día miércoles 10 de noviembre de 1999. La misma contó con la presencia de los siguientes señores legisladores: Doctor Heinz Moeller Freire, arquitecto Sixto Durán Ballén, señora Elba González, ingeniero Clemente Vásquez, ingeniero Lorenzo Saa, así como en representación del Bloque de la Izquierda Democrática, el doctor René Maugé Mosquera.

Firman la resolución Heinz Moeller, Presidente y el doctor Francisco Rocha Romero, Secretario de la Comisión. 
Superado el escollo del Congreso, dos días más tarde, el 10 de noviembre, firman el texto del Acuerdo, por duplicado, en los idiomas español e inglés, por el Gobierno del Ecuador el Ministro de Relaciones Exteriores Benjamín Ortiz Brennan y por el Gobierno de los Estados Unidos de América, Richard C. Brown, Negociador Especial Asuntos del Hemisferio Occidental. sic.

\section{Lo que jamás debió firmarse}

Un análisis minucioso del contenido y los términos del Acuerdo exigirían una extensión que desborda los alcances de este artículo; sin embargo, es necesario destacar lo que jamás debió aceptarse ni firmarse:

1.- El permitir la libre circulación de personas, aeronaves, navíos y vehículos norteamericanos, en las condiciones establecidas en el texto, consuma una violación total de la soberanía terrestre, marítima y aérea del Ecuador.

2.- El conceder al personal norteamericano y sus dependientes en el Ecuador una condición jurídica equivalente a la que proporciona al personal de la Embajada Americana, lo que de acuerdo a la Convención de Viena del 18 de abril de 1961 les confiere inviolabilidad personal, inviolabilidad de domicilio, inmunidad de jurisdicción penal, exención de pago de impuestos y gravámenes y algunos privilegios aduaneros. Conceder estos privilegios a las tropas y los mercenarios de una potencia extranjera es insólito e inadmisible.

3.- El renunciar a todo tipo de reclamación por daños causados, incluidas lesiones o muertes a ecuatorianos, viola los derechos humanos, el Código Civil y principios básicos del derecho internacional.

Con razón el ex Canciller Julio Prado Vallejo afirma que: "es un acuerdo sin el mínimo sentido de reciprocidad en el que todas las obligaciones están de la parte ecuatoriana y todos los derechos del lado norteamericano" 4 .

\footnotetext{
"Afirmación realizada en el Seminario: "El Plan Colombia, el ALCA y la crisis en el Ecuador", realizado en el Paraninfo de la Facultad de Ciencias Económicas de la Universidad Central del Ecuador, en Quito, el jueves 26 de julio del 2001.
} 


\section{Un plan de guerra}

Si el Acuerdo del 12 de noviembre de 1999 aparentaba ser un mecanismo de cooperación para luchar contra el narcotráfico, la lectura del Convenio Operativo de 2 de junio del 2000, firmado en Guayaquil por el Teniente General Luis Iturralde Córdova y el Mayor General James N. Solegan, Representante Comando Aéreo de Combate Sur de EE.UU., demuestra que los acuerdos tienen una finalidad militar. El lenguaje utilizado, la planificación, los mandos, las misiones nos permiten advertir que los Estados Unidos de América se ha posesionado de Manta para implementar sus proyectos geoestratégicos. La Base de Manta se encuentra bajo el Comando Operativo del Comando Sur del Ejército de Estados Unidos. La función estratégica militar del Comando Sur es vigilar toda la masa terrestre que se extiende desde Guatemala hasta Argentina. Las tareas que cumple el Comando Sur son:

- Mantener la seguridad de los Estados Unidos y sus accesos australes.

- Ayudar a los ejércitos latinoamericanos a combatir la insurgencia, el terrorismo y el narcotráfico.

- Revertir la influencia cubana.

- Adelantar los objetivos de la política exterior de Estados Unidos.

- Incrementar la influencia militar de Estados Unidos en la región ${ }^{5}$.

Los norteamericanos saben que: "La política cambia, pero no la geografía. Este hemisferio es aún la mitad del globo, las Américas, nuestra mitad. Nuestro futuro -geoestratégico, económico, social y político- debe estar asegurado por un sistema hemisférico de seguridad" 6 .

\footnotetext{
${ }^{5}$ Gregorio Selser, Los documentos de Santa Fe / y II. Universidad Obrera de México, México, 1‥ Edición,

${ }^{6}$ Gregorio Selser, Ob. Cit. P. 77.
} 


\section{Se viola la Constitución}

Al firmar los Acuerdos sobre la Base de Manta Jamil Mahuad violó lo que dispone la Constitución Política del Estado en el Artículo 171, numeral 13, que le obliga a "Velar por el mantenimiento de la soberanía nacional y por la defensa de la integridad e independencia del Estado".

Se atropelló también los artículos 130 , literal 7,161 , literal 2 , que obligan al Congreso Nacional a aprobar los tratados internacionales que establezcan alianzas militares; además, se burló al Congreso al desconocer la disposición contenida en el Art. 162 que señala que la aprobación la hará el Congreso en pleno, "en un solo debate y con el voto conforme de la mayoría de los miembros". También se ignoró lo dispuesto en el Art. 276 de la Constitución, literal 2, que establece como competencias del Tribunal Constitucional: Dictaminar de conformidad con la Constitución, tratados o convenios internacionales previo a su aprobación por el Congreso Nacional. De cara a todos estos atropellos a la Carta Magna del Estado más de 1000 representantes de diversas organizaciones populares, de las 22 provincias del Ecuador, presentaron una demanda de inconstitucionalidad al Tribunal Constitucional. Se presentó así la oportunidad de que el Tribunal rescate su potestad, pero no lo hizo, peor aún, una mayoría formada por 5 de sus 9 miembros se vendió al Gobierno de Gustavo Noboa, en un almuerzo ofrecido por el Canciller Heinz Moeller, y, el 16 de enero del 2001, el Tribunal decidió:

Que, la Constitución no le otorga competencia a este Tribunal para conocer y resolver demandas de inconstitucionalidad de tratados o convenios internacionales.

Que,... este Tribunal es incompetente para pronunciarse sobre la constitucionalidad o inconstitucionalidad del instrumento internacional impugnado.

Resuelve:

Desechar la demanda por improcedente. 
Cuatro de los ministros del Tribunal Constitucional votaron en contra de la resolución. Pero es digno de destacar que, en el voto salvado de los ministros doctores Hernán Rivadeneira Játiva y Marco Morales Tobar se establece que la demanda tiene los sustentos legales y constitucionales suficientes y, por lo mismo, no podía desecharse. Rivadeneira sostiene:

"Si se revisa el texto del Acuerdo o Convenio, así como el instrumento complementario referente a los temas operativos, se puede claramente advertir que se refiere a un tema de territorialidad (existe la concesión por lo menos por diez años para que militares de un país extranjero puedan acceder e ingresar a la Base, así como a otras instalaciones relacionadas con ella) y se trataría también de una alianza política y militar, pues es evidente que se utiliza una base militar por parte de militares y para acciones de carácter bélico"'.

\section{Ecuador un país sin narcotráfico ni guerrilla}

Conculcar la soberanía territorial, aérea y marítima del Ecuador para combatir al narcotráfico y al terrorismo, que es el nombre que dan los norteamericanos a la insurgencia, resulta insólito en el Ecuador. La verdad es que nuestro País, como lo demuestran todos los estudios serios, no es importante en casi ninguno de los ciclos de la economía política de las drogas. Somos país de tránsito y consumo interno marginal; $y$, ni siquiera la crisis económica y social, desatada por el mayor atraco de nuestra historia, en el que los banqueros corruptos asaltaron los ahorros de los depositantes, han modificado esa tendencia. Más aún, en la segunda mitad del siglo XX, los intentos de desarrollar la lucha político militar fueron más bien esporádicos y débiles. Homologar la situación del Ecuador con las de sus vecinos a través de la Base de Manta, el Plan Colombia y la Iniciativa Regional Andina, es, en si mismo, una demostración de que los verdaderos objetivos del Imperialismo marchan por otro sendero.

${ }^{7}$ Registro Oficial No. 260, martes 6 de febrero del 2001. 


\section{El Plan Colombia y la IRA}

En el discurso oficial la Base de Manta y el Plan Colombia se relacionaban en tanto mecanismos de combate al narcotráfico. Pero desde 1998 en que circuló en Colombia el primer borrador del Plan como una especie de Plan Marshall para Colombia, cuyos objetivos lo vinculaban con la promoción del desarrollo en las zonas marginales y fronterizas de ese país hermano, hasta la versión definitiva que se habría preparado antes del viaje del Presidente Andrés Pastrana a la ONU y la Casa Blanca, en septiembre de 1999, donde fue recibido por Bill Clinton, han pasado muchas aguas debajo del puente: La lucha antinarcóticos, por medio de la fumigación aérea con glifosatos y el simultáneo proceso de paz en la Zona de distensión de San Vicente del Caguán, son hoy dos estrategias fracasadas y sepultadas. Lo único que queda en pie del Plan Colombia original es el armamento norteamericano.

Introducido a Colombia y la creciente presencia de los asesores norteamericanos, la falsa presunción señalada en el documento de que: "Colombia ha asumido el liderazgo en la lucha mundial contra las drogas". Parte de un grave desconocimiento de la magnitud, complejidad y diversidad del problema de la droga en el mundo, en el que la coca es apenas uno de sus ingredientes. Por otro lado, insistir en la satanización de los cultivos de coca y en la fumigación área, es hacer de los campesinos, que la cultivan por razones de supervivencia, los principales culpables del narcotráfico, lo cual es absolutamente falso, pero además, implica graves daños para la biodiversidad amazónica y para los indígenas y campesinos pobres que sobreviven en esas regiones. Estudios serios sobre la estrategia de erradicación área con glifosatos demuestran que:

1.- Es imposible para un piloto, por experimentado que sea, evitar la fumigación indiscriminada de cultivos ilegales pero también legales, de fuentes de agua y de lugares en los que viven campesinos e indigenas.

s Plan Colombia, Desde Abajo, Suplemento Especial, Bogotá, Noviembre de 1999, p. 7. 
2. - El uso de herbicidas de amplio espectro, aplicados por vía aérea, causa graves e innecesarios problemas de salud en personas y animales, contamina el suelo, el aire, el agua y los alimentos, y destruye cultivos de pancoger, animales de cría y peces, y atenta contra la biodiversidad de flora y fauna?

El fracaso del proceso de paz impulsado por el gobierno de Andrés Pastrana y la victoria electoral de Álvaro Uribe Vélez si bien han determinado una intensificación dramática de las fumigaciones de los cultivos de coca, en una política que parece dirigida más bien a lograr la masiva migración de los campesinos a las ciudades, para dejar sin bases sociales a las FARC-EP y el ELN, corresponde también a una prioridad que se quedó en el pasado.

El ataque a las Torres Gemelas en Nueva York, el 11 de septiembre del 2001, cambió muchas cosas en el mundo pero también en la región andina. En la agenda global la lucha contra el narcotráfico fue superada por la guerra interminable contra el terrorismo anunciada por el Presidente George Bush.

\section{La estrategia de seguridad nacional del Imperio}

El 20 de septiembre del 2002, el Presidente de los Estados Unidos de América, George Bush, hijo, al enviar al Congreso el documento: "La estrategia de seguridad nacional de Estados Unidos", proclamó que Estados Unidos es el poder supremo del mundo y que no tolerará ningún desafío a su ventaja de poder, subrayando que su país "debe y tiene que mantener la capacidad para derrotar todo intento de un enemigo, sea un Estado o un actor no-estatal, de imponer su voluntad sobre Estados Unidos, nuestros aliados, 0 nuestros amigos". Bush se autoatribuye "la capacidad ilimitada de utilizar la fuerza para moldear el mundo de la manera que con-

\footnotetext{
${ }^{9}$ Elsa Nivia, Las fumigaciones áreas sobre cultivos ilícitos sí son peligrosas- Algunas aproximaciones. Conferencia en el Instituto Hemisférico de las Américas, Universidad de California, Davis, mayo 17 -19, 2001. La autora es Ingeniera Agrónoma y Lic. en Biología y Química.

${ }^{10}$ La Jornada, México, sábado 21 de septiembre del 2002.
} 
sideran mejor". La estrategia significa que los Estados Unidos abandonan la llamada política de disuasión y no proliferación, que ha sido el eje de su política exterior durante los últimos 50 años. En su lugar se promueve la "contraproliferación", o sea el desarme obligado de todo poder que desafíe o represente una amenaza para los Estados Unidos. Esa política se complementa con los elementos diseñados por el mismo Bush, después del 11 de septiembre del 2001, según los cuales las Fuerzas Armadas norteamericanas para combatir el terrorismo pueden actuar conjuntamente con otros Estados o de modo unilateral.

\section{El pequeño Bush de Colombia}

Entre los objetivos -mediatos o inmediatos- de las fuerzas imperiales no deberíamos descartar la posibilidad de que, como lo pide a gritos, el pequeño Bush de Colombia, Álvaro Uribe Vélez, los Estados Unidos decidan poner en marcha, simultáneamente o por etapas, la intervención regional contra la insurgencia colombiana que viene planificando el Jefe del Comando Sur de las Fuerzas Armadas norteamericanas. No en vano el gobierno cliente de Colombia se ha transformado, en los últimos años, en el tercer receptor mundial de ayuda militar, después de Israel y Egipto ${ }^{11}$. En este caso los polígonos de tiro que, hasta ahora los veíamos tan lejanos, pasarán a nuestra propia casa y algunos recién podrán comprender que las Bases Militares -como las de Manta- no son un juego de niños para el poderoso Imperio. La agresión a Colombia, concebida y trabajada durante más de una década en el contexto de la Iniciativa Regional Andina, buscaría derrotar a la curtida y heroica insurgencia de las FARC y el ELN, pero también dar el golpe definitivo al Gobierno constitucional y progresista del Coronel Hugo Chávez y crear un nuevo cerco sanitario, desde el mundo andino, contra el enorme Brasil que, bajo la dirección experimentada de Lula y el PT, busca cambiar su destino, apoyándose en la fuerza de su pueblo y en la gigantesca riqueza que significa la amazonia.

\footnotetext{
${ }^{11}$ En marzo del 2003, en el Centro de Estudios Colombianos, la embajadora Anne Patterson, recordó que su gobierno ha entregado a Colombia 1,700 millones de dólares para el Plan Colombia; una partida extraordinaria para capacitación antisecuestro; 6 millones de dólares para protección de infraestructura
} 
Que el Imperialismo es ágil y juega con todas las fichas no cabe la menor duda, lo sabemos los ecuatorianos que hemos visto, en semanas recientes, la mutación asombrosa del jefe militar del 21 de enero del 2000 que, de aliado del movimiento indígena y popular busca transformarse en el mejor aliado de Bush en la región andina. Desde luego, las determinaciones geoestratégicas del Imperio buscan imponerse con el garrote del Plan Colombia y la Iniciativa Regional Andina, pero también con la zanahoria del Mercado Común de las Américas y el pueblo mexicano sabe, por haberlo sufrido en carne propia, lo que significan los Tratados de Libre Comercio diseñados por el Imperio que nos desprecia.

\section{El papel de los militares ecuatorianos en la estrategia regional}

Desde que asumió la Presidencia de Colombia Álvaro Uribe Vélez ${ }^{12}$, la Patria de Gaitán y García Márquez vive un creciente proceso de fascismo como preludio de la guerra total contra la insurgencia. En Colombia los Estados Unidos no apuestan a una intervención militar directa, como las que hemos visto en Afganistán e Irak. Al parecer la estrategia diseñada por el Comando Sur busca comprometer a las Fuerzas Armadas de los países vecinos de Colombia en una acción coordinada con los militares y policías colombianos, bajo la dirección de los asesores norteamericanos. El jefe del Comando Sur de Estados Unidos, James Hill, en una visita que realizó a Quito en octubre del 2002, planteó abiertamente al Gobierno de Gustavo Noboa la necesidad de que las Fuerzas Armadas del Ecuador intervengan en el conflicto colombiano. El Vicecanciller Jaime Merchán declaró entonces públicamente que: "Ecuador no se involucrará en el conflicto interno colombiano, ni será parte de una fuerza multinacional"13.

La Embajadora de los Estados Unidos en Ecuador, Kristie Kenney, ha explicado en forma más clara las tareas que requieren del Ecuador y sus Fuerzas Armadas:

"nadie, nadie quiere que Ecuador llegue con sus tropas a Colombia. Lo importante es que Ecuador, que debe ser un buen vecino,

12 Joseph Contreras, Biografía no autorizada de Álvaro Uribe Vélez (El Señor de las Sombras), Editorial La Oveja Negra, Bogotá, 1ㄹ. Edición, mayo del 2002.

${ }^{13}$ Diario "HOY", Quito, jueves 17 de octubre del 2002, 1a. Página. 
cierre la frontera y cumpla con su parte para evitar actividades ilícitas. $Y$, sobre todo, hay que evitar que el problema de Colombia llegue al Ecuador para que se mantenga como una isla de paz. Eso quiere decir que darle oportunidad al colombiano de que resuelva su problema es no dejar abiertas rutas de escape a los guerrilleros y a los narcotraficantes ${ }^{14}$.

Es la estrategia del yunque y el martillo que han denunciado algunos jefes militares ecuatorianos en servicio pasivo como la tarea estratégica que el Comando Sur asigna a las Fuerzas Armadas del Ecuador en la guerra regional contra las FARC-EP y el ELN.

¿Cuál es la actitud del Presidente Lucio Gutiérrez frente a este deseo de implicarnos en la guerra interna de Colombia?

El lunes 11 de febrero del 2003 Lucio es recibido por Bush, analizan, entre otros temas, los relacionados con la Base de Manta y la intervención del Ecuador en el Plan Colombia. Al salir de la reunión anuncia a la prensa nacional y extranjera: "Le hemos dicho que queremos convertirnos en el mejor aliado y amigo de Estados Unidos, en la lucha por la paz en el mundo, por fortalecer la democracia, por reducir la pobreza, por combatir el narcotráfico y por acabar con otra lacra, el terrorismo"15. El mismo día, en horas de la mañana, en un acto público, en el Centro de Estudios Estratégicos Internacionales, definió como una de las prioridades de la política oficial de su gobierno el luchar contra el terrorismo y el narcotráfico. 'Si no apoyamos, todos, de manera más protagónica a (Álvaro) Uribe, seguramente se seguirá sacrificando la vida de más gente". Para sentenciar: "Uribe lleva de una manera muy adecuada una posible solución al problema (de Colombia)".

Para demostrar, de inmediato, los resultados de la subyugación a la estrategia imperial en la región, Gutiérrez anunció que Estados Unidos incrementará su ayuda a Ecuador con 116 millones de dólares ${ }^{16}$. Al parecer las ayudas incluyen pertrechos militares para la frontera norte.

\footnotetext{
${ }^{14}$ Diario "El Universo", Guayaquil, jueves 6 de marzo del 2003, p. A4.

${ }_{15}$ Diario "El Comercio" de Quito, miércoles 12 de febrero del 2003, p. A 3.

${ }^{16}$ Diario "Hoy" de Quito, jueves 13 de febrero del 2003, 1a. Página.
} 
Para que nadie dude de su adherencia al militarismo proimperialista, en una entrevista concedida a The Washington Times afirmó que: "la población de la Isla (de Cuba) no debe sufrir las consecuencias de la política de Castro" ${ }^{17}$.

La Canciller Nina Pacari ha formulado declaraciones que demostrarían cierto nivel de contradicción con los señalamientos del Presidente. ¿Se puede engañar al Imperio en un asunto de esta magnitud? ¿Quién dice la verdad? ¿Quién miente? Lo único cierto es que tenemos más de 14000 efectivos militares en la línea de frontera con Colombia. Cuando suenen los primeros tiros estaremos en la línea de combate. El Ecuador y sus Fuerzas Armadas, por Imposición del Imperialismo norteamericano, habrían elegido el peor momento de su historia para intervenir en una guerra que no es nuestra. La crisis económica, el fracaso de la dolarización y la evidencia de serios problemas internos en la conservación del armamento son apenas algunos indicadores de que el Gobierno debería actuar con más soberanía e independencia, tomando distancia de la demencial política internacional de Bush y Uribe y evitando, con sabiduría y grandeza, sacrificios innecesarios a nuestro pueblo que incluye también a los uniformados.

${ }^{17}$ Citado por el Diario "Hoy" de Quito, página A-3. 
